\title{
Convergence excess esotropia treated surgically with fadenoperation and medial rectus muscle recessions
}

\author{
R Jane Leitch, John P Burke, Ian M Strachan
}

\begin{abstract}
Convergence excess esotropia has been treated with bifocals, miotics, medial rectus recession(s), fadenoperation, or a combination of these. However, comparatively few studies on the sensory status of these patients exist. We present the sensory findings in $\mathbf{3 1}$ children treated surgically. Twenty-one had fadenoperations combined with bimedial rectus recessions, one had a fadenoperation alone, and nine had augmented bimedial rectus recessions. Five children (16\%) achieved bifoveal fusion, $22(71 \%)$ had varying degrees of peripheral fusion, and four $(13 \%)$ had no detectable binocularity after a mean postoperative follow-up of $2 \cdot 4$ years.
\end{abstract}

Convergence excess esotropia is characterised by normal binocular single vision for distance (with glasses if required) but esotropia on accommodation for near fixation. Its traditional treatment has been with bifocals ${ }^{1}$ and occasionally miotics. However, doubts have been raised about the appropriateness of long term treatment by either of these methods. ${ }^{2}$

The results with conventional surgery, namely unilateral or bilateral medial rectus recessions, have been mixed, while the use of the posterior fixation suture alone or in conjunction with conventional surgical techniques is accepted as an alternative. We review the sensory findings in 31 consecutive cases of convergence excess esotropia after primary surgical treatment.

\section{Patients and methods}

Thirty-one cases of convergence excess esotropia were treated surgically over a five-year period. None had been previously treated with miotics or bifocals. Twenty-one children had bilateral medial rectus recessions combined with posterior fixation sutures placed as far posteriorly as the intraconal fat pad would allow (12-14 $\mathrm{mm}$ from the original insertion). $1 \mathrm{~mm}$ of medial rectus recession was performed for each 3 prism dioptres of distance angle measured. Two

TABLE I Preoperative near deviation (prism dioptres), postoperative alignment, and steroacuity in 21 patients with improved binocular status after surgery

\begin{tabular}{|c|c|c|}
\hline & $\begin{array}{l}\text { Fadenoperation plus } \\
\text { recession group }(21 \text { cases })\end{array}$ & $\begin{array}{l}\text { Bilateral recession } \\
\text { group }(5 \text { cases })\end{array}$ \\
\hline $\begin{array}{l}\text { Age at surgery (years) } \\
\text { Age at end of follow-up } \\
\text { Preop. near deviation (PD) } \\
\text { Postop. near stereoacuity }\left(\operatorname{arc}^{\circ}\right) \\
\text { Present near alignment of } \\
\text { each patient }\end{array}$ & $\begin{array}{l}5 \cdot 7 \text { (range } 2 \cdot 5 \text { to } 9 \cdot 0) \\
8 \cdot 1 \text { (range } 5 \cdot 0 \text { to } 12 \cdot 0 \text { ) } \\
35 \cdot 6 \text { (range } 25 \text { to }>45 \text { ) } \\
\leqslant 60^{\circ} 4 \text { cases } \\
>60^{\circ}-\leqslant 140^{\circ} 7 \text { cases } \\
>140^{\circ}-\leqslant 800^{\circ} 5 \text { cases } \\
12 \mathrm{E}^{\circ} ; 1 \mathrm{X}^{*} \\
3 \text { microtropia }\end{array}$ & $\begin{array}{l}6 \cdot 8(\text { range } 5 \cdot 5 \text { to } 7 \cdot 8) \\
9 \cdot 6 \text { (range } 8 \cdot 0 \text { to } 15 \cdot 0) \\
32 \cdot 0 \text { (range } 25 \text { to }>45 \text { ) } \\
\leqslant 60^{\circ} 1 \text { case } \\
>60^{\circ} \leqslant 140^{\circ} 3 \text { cases } \\
>140^{\circ} \leqslant 800^{\circ} 1 \text { case } \\
5 \mathrm{E}\end{array}$ \\
\hline
\end{tabular}

posterior fixation sutures (PFS) were placed in each medial rectus muscle (the superior and inferior sutures incorporating approximately the superior and inferior one-fourths of the muscle respectively) with 5:0 Dacron. One patient was treated with posterior fixation sutures (fadenoperation) alone. Nine cases had bilateral symmetrical augmented medial rectus recessions where $1 \mathrm{~mm}$ of recession was performed for each 3 prism dioptres of near angle up to a maximum of $6.5 \mathrm{~mm}$ of recession per eye. Our aim was to reduce the near deviation to less than 10 prism dioptres (PD) so that suppression might be reduced or eliminated and the potential for fusion facilitated. Tables 1 and 2 compare the sizes of the near angles preoperatively with the most recently measured deviations and outline the most recent sensory status of all 31 patients.

\section{Results}

Thirty-one cases of convergence excess esotropia were assessed (17 males, 14 females). Their mean age when first seen was 3.7 years (range 1.5 to 6.8 years). Their mean age at surgery was 5.7 years (range 2.5 to 9.0 years), while their mean age at most recent assessment was $8 \cdot 1$ years (range $5 \cdot 0$ years to 15.0 years). The child who had posterior fixation sutures alone had a near angle of 30 prism dioptres. Five of 22 children who had posterior fixation sutures required further surgery, with resultant satisfactory realignment. Two had been initially overcorrected, while three were initially undercorrected.

There was a significant overall reduction in the size of the near deviation postoperatively, most cases being phoric or with a residual small angle manifest squint (Table I). In many cases a microtropia was noted for near with the 4dioptre prism test. There was a significant improvement in binocularity and in stereoacuity postoperatively in 21 children $(68 \%)$ (Table I). In eight cases (26\%) (Table II) cosmesis was improved without a noticeable improvement in binocularity. Binocularity was lost in two children, though cosmesis was satisfactory. There were no cases of convergence weakness and no intraocular complications postoperatively. Lateral incomitance, while common, was not marked or symptomatic in any of our patients following fadenoperation.

\section{Discussion}

Despite having binocular single vision for distance fixation, children with convergence excess esotropia are not infrequently difficult to treat and results are often disappointing. Miotics were reported to be ineffective. ${ }^{2}$ Moreover, they have numerous side effects, some of which may 
TABLE II Preoperative near deviation (prism dioptres) and postoperative alignment in 10 patients, with little change (8 cases) or apparent deterioration (2 cases) in postoperative binocular status

\begin{tabular}{|c|c|c|c|}
\hline & $\begin{array}{l}\text { Fadenoperation plus } \\
\text { recession group ( } 5 \text { cases) }\end{array}$ & $\begin{array}{l}\text { Bilateral recession } \\
\text { group ( } 4 \text { cases) }\end{array}$ & $\begin{array}{l}\text { Fadenoperation } \\
\text { (l case) }\end{array}$ \\
\hline $\begin{array}{l}\text { Age at surgery (years) } \\
\text { Age at end of follow-up } \\
\text { Preop. near deviation (PD) } \\
\text { Postop. near stereoacuity } \\
\left(\text { (arc }^{\circ}\right) \\
\text { Present near alignment }\end{array}$ & $\begin{array}{l}5 \cdot 1(\text { range } 4 \cdot 5 \text { to } 6 \cdot 5) \\
7 \cdot 2(\text { range } 6 \cdot 0 \text { to } 9 \cdot 1) \\
40(\text { range } 30 \text { to } 45) \\
2 \text { small PFR } \\
3 \text { no BSV } \\
3 \text { E‡, } 2 \mathrm{ET}^{\dagger}\end{array}$ & $\begin{array}{l}5 \cdot 8(\text { range } 3 \cdot 1 \text { to } 9 \cdot 0) \\
8 \cdot 1 \text { (range } 3 \cdot 1 \text { to } 9 \cdot 8) \\
31(\text { range } 20 \text { to } 40) \\
2 \text { small PFR } \\
200^{\circ}, 400^{\circ} \\
1 \mathrm{E}, 1 \mathrm{X},{ }^{\prime \prime} 2 \mathrm{ET}\end{array}$ & $\begin{array}{l}4 \cdot 0 \\
6 \cdot 0 \\
30 \\
\text { Small PFR } \\
1 \mathrm{E}\end{array}$ \\
\hline
\end{tabular}

${ }^{\cdot} \mathrm{PFR}=$ Prism fusion range. ${ }^{\dagger} \mathrm{BSV}=$ binocular single vision. ${ }^{\dagger} \mathrm{E}=$ esophoria. ${ }^{\prime} \mathrm{ET}=$ esotropia. ${ }^{\prime \prime} \mathrm{X}=$ exophoria.

be severe. ${ }^{3}$ The traditional treatment, more especially in the United States of America, has been with bifocals, ${ }^{1+}$ but little information is available on the sensory findings in such patients and the efficacy of this therapy in comparison with other methods. ${ }^{2+5}$ Indeed, correct fitting of bifocal and compliance with their wear is often less satisfactory in active children than in adults.

Von Noorden et al evaluated bifocals in 84 children. ${ }^{+}$Twelve $(14 \%)$ patients were able to fuse without bifocals at the end of therapy; in 19 (22\%) the bifocal power could be reduced. Thirty-nine $(46 \%)$ remained dependent on bifocals, and in 14 (17\%) fusion had deteriorated in spite of therapy. Tillson and Pratt-Johnson ${ }^{2}$ suggested that bifocals were ineffective even in compliant patients in preventing the eye from turning in at all near distances. In their series of 120 children surgery (bimedial rectus recessions) was performed only if children had a distance esotropia greater than 10 prism dioptres. They noted that the sensory results in those prescribed bifocals were comparable with those treated surgically. Only $9 \%$ of those treated with biofocals or surgery achieved bifoveal binocular single vision for near ( $<60^{\circ}$ arc) and distance, while $76 \%$ achieved peripheral fusion. The children in our study differed in that none had a documented distance esotropia, and a different surgical procedure was employed. Only five cases $(16 \%)$ achieved bifoveal binocular single vision for near and distance (four of 21 cases of posterior fixation sutures with medial rectus muscle recessions; one of nine cases of bilateral medial rectus muscle recessions), while $22(71 \%)$ cases achieved variable stereopsis. In two cases (6\%) binocular potential was lost despite cosmetically satisfactory alignment.

Conventional muscle surgery techniques have been used to treat convergence excess esotropia with mixed success. ${ }^{6-8}$ Kushner et al, ${ }^{9}$ believing that conventional recessions were associated with frequent undercorrections, conducted a prospective study of 46 patients with partially accommodative esotropia with a high AC/A ratio. One group had bilateral medial rectus recessions with posterior fixation sutures, while the other group had augmented bilateral medial rectus recessions. Their data suggested that better postoperative alignment was achieved by the latter procedure. Reynolds and Hiles ${ }^{10}$ used a variety of procedures in conjunction with the posterior fixation suture. Most of their bifocal wearers could discard their glasses, but further details on sensory findings were not published.

There are a number of conflicting reports on the variability in the postoperative deviation following either posterior fixation suture alone or in combination with medial rectus muscle recessions. ${ }^{11-13}$ Kushner $e t a l^{9}$ noted that three of 21 patients with combined bilateral medial rectus muscle recessions and posterior fixation sutures were overcorrected, while some were significantly undercorrected. In our series five of 21 cases required reoperation, with satisfactory realignment. None of our patients suffered vision threatening intraocular complications after a mean postoperative follow-up of $2 \cdot 4$ years. Lyons $e t a l^{1+}$ have recently retrospectively reviewed 100 fadenoperations and affirmed the relative safety of the procedure.

The traditional treatment of convergence excess esotropia (high AC/A ratio) in children has been with biofocals. We used the posterior fixation suture, bilateral medial rectus recessions, or a combination of these as a primary therapy. The results of postoperative alignment and steroacuity compare favourably with those previously published. We believe that the posteror fixation suture is an effective primary treatment of convergence excess esotropia when compared with the known advantages and disadvantages of existing therapeutic methods. ${ }^{1+15}$

The authors thank Jane Parkinson and the staff of the orthoptic department for their help with this study.

1 Parkes MM. Abnormal accomodative convergence in squint. Arch Ophthalmol 1958; 59: 364-80.

2 Tillson G, Pratt-Johnson JA. Sensory results following treatment of esotropia with convergence excess (high AC/A ratio). In: Ravault AP, Leak M, eds. Transactions of the Fifth International Orthoptic Congress LIPS. Lyon: 1984: 317-22.

3 Mein J, Harcout B. Diagnosis and management of ocular motility disorders. Oxford: Blackwell, 1986: 144-6.

4 Von Noorden GK, Morris J, Edelman P. Efficacy of bifocals in the treatment of accomodative esotropia. Am $\mathcal{F}$ Ophthalmo 1978; 85: 830-4.

5 Poole M, Strachan I. The surgical treatment of convergence excess. In: Campos EC ed. Proceedings of the Fifth International Strabismological Association. Rome: 1986: 399-44.

6 Albert DG, Lederman ME. Abnormal distance-near esotropia. Doc Ophthalmol 1973; 4: 27-36.

7 Rosenbaum AL, Jampolsky A, Scott AB. Bimedial recession in high AC/A esotropia. Arch Ophthalmol 1974; 91: 251-3. 8 Zak TA. Preliminary results of bimedial rectus recession in treatment of high AC/A ratio esotropia. In: Campos EC ed. Proceedings of the Fifth International Strabismological Association. Rome: 1986: 335-8.

9 Kushner BJ, Preslam MW, Morton GV. Treatment of partly accomodative esotropia with a high accomodative convergence-accomodation ratio. Arch Ophthalmol 1987; 105: 815-8.

10 Reynolds JD, Hiles DA. The posterior fixation suture for abnormal distance/near relationship esotropia. In: Reinecke RD, ed. Strabismus 11: Proceedings of the Fourth International $\mathrm{RD}$, ed. Strabismus 11: Proceedings of the Fourth International
Strabismological Association. New York: Grune and Stratton,

11 Von Noorden GK. An alternative to marginal myotomy. $A m \mathcal{F}$ Ophthalmol 1982; 94: 285-9.

12 Spielmann A, Laulon J. Action of recessions and resections when associated with Cupper's fadenoperation in esotropia. Statistical results, in: Reinecke RD, ed. Strabismus 1 Proceedings of the 2nd International Strabismological Association. New York: Grune and Stratton, 1978: 355-65.

13 Conrad HG, Treumer H. Zum wirkungsprofil der fadenoperation. Klin Monatsbl Augenheilkd 1981; 178: 174-9.

14 Lyons CJ, Fells P, Lee JP, McIntyre A. Chorioretinal scarring following the fadenoperation. A retrospective study of 100 procedures. Eye 1989; 3: 401-3.

15 De Decker W. The fadenoperation. When and how to do it. Trans Ophthalmol Soc UK 1981; 101: 264-70. 